\title{
LA CATALUÑA DE ALONSO QUIJANO
}

\author{
JOAN GIMÉNEZ I BLASCO \\ IES Vilatzara ${ }^{\mathrm{a}}$
}

\begin{abstract}
RESUMEN
Miguel de Cervantes ubicó algunos pasajes de su obra más significativa en Cataluña. Pero los trazos con que describe la realidad catalana -a caballo de los siglos XVI y XVII- constituyen, necesariamente, una aproximación mediatizada por la personalidad de Don Quijote. La economía catalana de esta época estaba abriéndose camino en todos los ámbitos susceptibles de generar ganancias. Lejos de los esplendores de la brillante etapa medieval, era necesario reorientar la agricultura, potenciar las producciones más competitivas y buscar mercados. A ello se dedicaron unas nuevas generaciones tan distantes de las viejas oligarquías patricias como de las veleidades levantiscas de la nobleza marginal. Estaban trazando, acaso sin saberlo, los caminos de la modernidad.
\end{abstract}

Palabras clave: Cervantes, Generalitat, fiscalidad, comercio, agricultura, protoindustria

\section{ABSTRACT}

Miguel de Cervantes placed some passages of his masterpiece in Catalonia. Nevertheless, the features he uses to approach the Catalan reality -halfway

a Vilassar de Mar, 08340 Barcelona. 
between 16th and 17th centuries- are obviously influenced by Don Quixote's personality. At that time, the Catalan economy was making its way in every sphere of activity which could operate at a profit. Far away from that magnificent Middle Ages, agriculture had to be rearranged and it was necessary to promote the most competitive products and to try to find markets for them. New generations devoted themselves to this purpose, people who were equally distant from the old patrician oligarchies and from the fickleness of the marginal nobility. They were laying, perhaps without knowing it, the path to modernity.

Keywords: Cervantes, Generalitat, fiscal, commerce, agriculture, proto-industry JEL Classification: N53, N63, N73, N83

El autor del Ingenioso Hidalgo, además de los encendidos elogios que dedicó a la Ciudad Condal, ofreció algunas pinceladas sobre la realidad catalana en algunos ámbitos que debían ser los que más interés podían suscitar en los observadores procedentes del interior peninsular. Así, la referencia al bandolerismo, encarnado en el famoso pasaje en que Don Quijote se encuentra con Perot Rocaguinarda, en el cual se menciona la existencia de las facciones de los Nyerros y Cadells; la interesante descripción de las galeras en el puerto de Barcelona, y la persecución de la nave argelina, ilustran no sólo el conocimiento que el autor tenía de este tema por experiencia propia, sino también la cotidianeidad de uno de los temores que condicionaban la vida de las poblaciones costeras. Un aspecto digno de especial mención es la visita que Don Quijote realizó a una imprenta barcelonesa, con motivo de la cual el autor nos ilustra sobre las peculiaridades del mundo editorial que tan bien conocía. Todas estas referencias a la problemática catalana del momento son, necesariamente, unos reflejos fugaces de una realidad rica, compleja y cambiante como era la de la Cataluña a caballo de los siglos XVI y xVII.

Si, a su llegada a Barcelona, Don Quijote y Sancho, en lugar de encontrarse con Antonio Moreno -personaje de perfiles más bien romos, preocupado por niñerías como la cabeza encantada - se hubiera encontrado, por ejemplo, con Jeroni Serra Arnau, su percepción de la realidad catalana habría sido, seguramente, más prosaica, pero mucho más rica en matices. La elección de este personaje, no literario sino real, tiene una intencionalidad bien definida. No se trata de una personalidad relevante de la vida política y social de su época en el Principado. Un elemento importante es que no era hijo del Cap i Casal, con lo que se rehuye la fácil tentación de tomar la parte por el todo -es decir, hablar de historia de Cataluña refiriéndose únicamente a Barcelona-, elemento muy frecuente en la historiografía catalana.

Jeroni Serra Arnau había nacido en Mataró, a mediados del siglo XvI, en una familia de propietarios vinculados a importantes masos locales. A pesar de que en 
el inventario post mortem de sus bienes ${ }^{1}$ se describían ocho piezas de tierra dedicadas al cultivo de la vid y, en el mismo documento notarial, se hacía una detallada relación de sus bodegas, con una capacidad superior a los $356 \mathrm{Hl}$., la documentación nunca le cita como labrador. El mismo inventario ofrece algún otro dato significativo, al detallar que había realizado diferentes préstamos bajo la forma de censal por valor de 600 libras. Otras fuentes muestran a este dinámico personaje tomando parte en diversas actividades económicas. Fue un activo exportador de vinos $^{2}$, y participó con asiduidad en el negocio de los seguros marítimos ${ }^{3}$. Dentro de esta actividad es particularmente significativa la operación en la cual garantizó parte del cargamento de la nave Santa Maria i Sant Elm que, con cien cascos de vino, había de dirigirse de Mataró a Lisboa. En la póliza del seguro se hizo especial mención de garantizar el rescate del capitán en caso de que cayera en manos corsarias $^{4}$. Sin embargo, todas estas actuaciones, con ser significativas, no llegan a dar el tono adecuado para conocer la verdadera significación económica del personaje.

Efectivamente, en la dimensión económica de su personalidad, Jeroni Serra Arnau destacó en su gestión como tauler de la Generalitat. La Diputació del General o Generalitat de Catalunya había conseguido aumentar progresivamente el número de sus competencias desde su fundación en la Edad Media. Entre éstas cabría destacar el cobro de impuestos votados por la Cort General que habrían de servir para satisfacer las peticiones de subsidios por parte del monarca. Uno de estos impuestos, que gravaba la importación y exportación de mercaderías extra regnum, era conocido como dret d'entrades i eixides. Existían unos puntos de recaudación en los lugares en que la intensidad del tráfico comercial lo hacía aconsejable, centros fiscales que recibían genéricamente el nombre de taules del General, y los responsables de su gestión, por extensión, eran llamados taulers.

En el año 1590, los responsables de la taula de Mataró eran Jeroni Serra Arnau y Gaspar Arnau ${ }^{5}$, el primero de los cuales mantendría en sus manos el control de este importante instrumento económico durante más de cuarenta años, según confesión propia. En el año 1599, a la vista de los numerosos fraudes que se rea-

\footnotetext{
Museo Arxiu Santa Maria de Mataró (MASMM), Inventaris, 12.IX.1620.

2 Archivo de la Corona de Aragón (ACA) Arx. Not. Mataró, B 39, 24.X.1597.

${ }^{3}$ En tres ocasiones asegura diferentes cargamentos de barrilla, Salsola soda, desde Alicante, hasta su destino, los hornos de vidrio locales: ACA, Arx. Not. Mataró, 161, 12.I.1600. ACA. Arx. Not. Mataró, 180, 14.X.1602. ACA. Arx. Not. Mataró, 183, 15.X.1606. Aseguró también, conjuntamente con otros individuos, diversas importaciones por vía marítima de trigos procedentes del campo de Tarragona con destino a Mataró. ACA. Arx. Not. Mataró, 181, 9.XI.1604 y 23.XI.1604. ACA. Arx. Not. Mataró, 191, 21.I.1614.

${ }^{4}$ «En cas que Bartomeu Bertran sie pres de moros o infels e volran enviar per ell per rescatar-lo que encontinent y sense tardança alguna los asseguradors [...] sien tinguts y obligats en pagar». ACA. Arx. Not. Mataró, 138, 1.VI.1588.

${ }^{5}$ ACA. Generalitat. Visita del General, $n^{\circ} .13 .1590$.
} 
lizaban en las diferentes taulas y, muy en concreto, en la de Mataró, la Cort General dictó una serie de normas que intentaban evitar que, gracias al trato favorable que recibían los mercaderías que entraban por esta población, se desviase una parte importante del negocio que anteriormente lo hacía a través del puerto de Barcelona, todo ello en perjuicio de las finanzas de la Generalitat ${ }^{6}$.

La connivencia de los responsables locales y hasta de los altos cargos de esta institución en los fraudes fue conocida en la época ${ }^{7}$ y ha sido estudiada por Elliott, entre otros ${ }^{8}$. La evidencia, no sólo de los fraudes, sino de la corrupción en algunos funcionarios, hizo necesaria la activa presencia de la institución responsable del seguimiento de la actuación de los funcionarios, la visita del General ${ }^{9}$. El año 1611, el procurador fiscal de la visita del General, Jaume Regàs, inició una exhaustiva visita a la taula mataronesa, de la cual eran responsables Jeroni Serra Arnau

\footnotetext{
${ }^{6}$ Deliberaciones de la Cort General de 1599: «Item per quant en la Taula de Mataró de poch ensà los francesos fan gran comers en la platja de dita vila y si feyhen moltíssimos fraus de hont se han seguits molts danys al General y en particular a la Taula de Barcelona per estar tant cerca de la dita vila, per ço mana la dita Cort que lo receptor y credencer de les entradas y exidas de la dita taula sien obligats d.esta hora en avant de aportar un llibre de manifest hont sien obligats de continuar en dit llibre totas las robas y mercaderias que en dita plaja se descarregaran y que los patrons y capitans de ningun vesell que donarà fondo en dita plaja a pena que sien caygudes en frau totas las robas que portaran, que ans de descarregar en terra cosa ninguna hagen de manifestar als dits taulers totas las robas $y$ mercaderias que volrran descarregar y firmar se en lo dit libre del manifest de llur mà al peu, del que los dits taulers hauran continuat y si al contrari serà fet per los dits taulers sien cayguts en pena de sinquanta lliures donant ne la meytat al acusador». ACA. Generalitat, 1099, fol. 1043.

${ }_{7}$ «Altres en lo número dels quals, son principalment los Receptors, Exactors, Guardas, Estimadors, y semblants Ministres de la exacció dels drets, tributs é imposicions, que ab especial jurament se obligan a la fi de exacció de aquells, se atrevexen, y procuran, cegats del amor o temor inordenat, y olvidats del jurament de fidelitat, fraudar los mateixos drets per si propris, per sos parents, per sos affins, y sos amichs: y encara ensenyar al altres diferents arts, y modos, ab que secretament, y sens perill de castich pugan comentrer semblants fraus. Altres, que encara que no són ministres, estan emperò obligats per rahó de son numenament en revelar las fraus, no dubtam romprer aquell, en dissimular las dels altres y encara en consentir, y concórrer secretament en ellas. Altres usant marcas, y senyals falsos, o prenent noms suposats de personas exemptas de la prestació dels tributs, procuran de tal manera fraudar aquells ab tan gran astucia, que de ordinari may apenas venen à pagarlos. Molts també per anar més segurs, als ministres a qui està comenada la exacció dels drets, ò ab prechs o ab diner o ab dàdivas los corrompen; per a que los remetan en tot o en part la paga de aquells. Altres finalment exposant sos béns a la pena estatuhida contra los fraudants, portan sas mercaderias secretament, y de nits, per llochs deserts, deixant lo cami real, ahont las guardas y exactors acostumar assistir, y regoneixer aquells pasatjers. Per a que no pugan ser ofesos ni regoneguts per aquells; despedint, y venent ditas mercaderias; y en las ciutats, y llochs de sa major seguretat secretament las introduheixen: per a que ab estos, y semblants modos y ab tota solicitut, y seguretat pugan deslliurar sos béns, y mercaderias de la justa prestació dels drets». Recopilació, pp. 56-57.

${ }^{8}$ Elliott (1977), Martí (1996), Llovet (2000).

${ }^{9}$ Ferro (1999), p. 408).
} 
y su yerno Antoni Pedró. Parece evidente que el procurador fiscal actuó en base a las denuncias recibidas ${ }^{10}$. De la lectura de los informes del fiscal se puede colegir una dudosa profesionalidad de los funcionarios en su cometido, pero más interesante es el detalle de los hombres y mercaderías que transitaban en esta improvisada frontera entre el litoral del Maresme y los territorios no catalanes.

El mercader catalán Joan Anglada expedía importantes cantidades de piñones y sardina salada que, según declaración propia, él mismo pescaba y salaba ${ }^{11}$. Otro testigo apuntaba que en épocas de sobreproducción de este mismo producto los excedentes se exportaban a Carbona, Livorno y Nápoles. Otros testimonios interesantes fueron los de Carlos Dinelli, mercader genovés residente en Barcelona y asociado al flamenco Bernarde de Iusti, quienes declararon comprar habitualmente el piñón en Granollers para embarcarlo en Mataró. Rafael Planes, droguero de Barcelona, declaraba haber comprado gran número de cuarteras a payeses que han menester diners y si adelantaba el pago uno o dos meses conseguía reducciones en el precio de tres y cuatro sueldos por cuartera.

Especial interés mereció a los visitadores el problema detectado con la importación de productos textiles cuya procedencia se sitúa en el Piamonte y en Génova. Los visitadores consideraron que muchos de estos productos habían sido declarados por un valor muy inferior al que en realidad tenían ${ }^{12}$. Pontius Rato, nizardo, testificó que importaba telas del Piamonte a través de la taula de Mataró.

\footnotetext{
${ }^{10}$ «A notícia del procurador fiscal de la visita del General, fama pública precehint, ha pervingut que en los llibres de les entrades y exides dels drets del General en la vila de Mataró del trienni proppassat aportat per Jeroni Serra Arnau, burgès, y Antoni Pedró, apotecari, taulers del General de dita vila de Mataró hi haurie molts grans errors en los despaigs de les mercaderies despatxades per cada hu dels dits taulers respective, assentant les mercaderies a molt manco preu del just valor de aquelles, y en una matexa jornada despatxar alguns partits de mercaderies de una matexa specie algun partit al preu just y los altres partits la meytat manco, y en particular se trobaran alguns partits despatxats per dits taulers de mercaderies sues propries y aquelles han assentades a molt manco preu del que valien, defraudant lo dret al General y de Galeres, y la ocasió que dits fraus se fan contra del General és perquè dits taulers de dita vila de Mataró, que són credenser y reseptor, són sogre y gendre, y quant lo hu despatxa mercaderies pròpries lo altre tauler no li contradiu, encara que y assenten molt manco preu. Y la ocasió és ésser tots dos sogre y gendre com està dit, lo que redunda tot en dany del General y segueyxen-se notables inconvenients, com sie ben cert que en via de dret lo official del General no pot servir de credenser a son sogre ni vice-versa, perquè lo hu no pot contradir al altre per la affinitat que y ha entre dit sogre y gendre». ACA. Generalitat, Visita del General 213. No. 137. Año 1611. Los subrayados se encuentran en el texto original.

11 «[...] dit Anglada despatxà dits dias [el piñón que] comprà en clofolla de pagessos y no de mercaders bestrahent los diners al més d.ells a differents preus y ell mateix lo feu secar y adobar en las golfas de sa casa, y després lo trencà per son compte propri y es home que fa negociatió particular ab pinyó y los més anys ne compra quatre o sinch centes quarteres.» ACA. Generalitat, Visita del General 213. No. 137. Año 1611.

12 «Interrogatus que diga si en lo llibre que aporta per rahó de son offici ha posades las robas y mercaderies ab lo just valor y preu de aquellas perquè la present visita té notíçia que las ha posadas a molt mancho valor del que valian aquellas y que diga quins partits són y
} 
A pesar de los esfuerzos del procurador fiscal, los responsables de la mesa de Mataró fueron absueltos a través de un subterfugio legal ${ }^{13}$. Que el tema se había cerrado en falso lo prueba que al cabo de cuatro años se realizó una nueva visita a la taula de Mataró que continuaba bajo el control de Serra i Pedro ${ }^{14}$, en cuya ocasión el caballo de batalla fue la importación de tejidos. El procurador fiscal, a la vista de los registros de la taula, constató el poco rigor que se observaba en la descripción de las entradas de tejidos, de los cuales no se anotaba ni el tiraje ni el peso, lo cual posibilitaba todo tipo de fraudes. Pero en esta ocasión se realizó un duro interrogatorio a los funcionarios, planteándoles la siguiente paradoja: ¿Cómo era posible que en el período de los tres últimos años no se hubiera anotado ninguna importación en los registros contables de telas finas, alemanas, batistas, etc., cuando era público y notorio que los negociantes y tratantes de estos artículos de Barcelona se proveían en Mataró de estos productos ${ }^{15}$ ? Una operación concreta que centró la atención de los inspectores fue una partida de 170 piezas de telas procedentes de Génova, desembarcadas por cuenta de Francisco Berardo y Juan Baptista de Negro, que no cumplía ninguna de las previsiones reglamentarias.

Pocos años después, ya fallecido Jeroni Serra Arnau, le substituyó al frente de la taula de Mataró otra destacada personalidad local, negociante y propietario de viñas, Joan Palau. Con motivo de la visita de $1623^{16}$, el procurador fiscal le acusó de vender grandes cantidades de vino a las galeras de Génova y de Nápoles sin exigir los derechos correspondientes a la Generalitat, con lo cual podía ofrecer a los proveedores de las galeras un precio más ventajoso que sus convecinos ${ }^{17}$. Un

quines mercaderies eran y de qui eran y perquè ho ha fet essent com és contra capítols de Cort y en dany del General. Et dixit:. «No sé que en ma vida hage despachat ningun partit a mancho preu de son valor y he fet sempre mon offici en lo que tocave al beneffici del General.»» ACA. Generalitat, Visita del General 213. No. 137. Año 1611.

13 ACA. Generalitat. Visita del General, 56. Núm. 91.

${ }^{14}$ ACA. Generalitat. Visita del General, 56. Núm. 36. 1615.

15 «[...] y és cert que no havent-se en tot aquest trienni propassat despaigs algú en dita vila y collecta de Mataró de teles fines, tenint notítica lo procurador fiscal que en dita taula ne arriban tantes com són alemanyetas, alemanyas de saquet, batistas fines y altres telas semblants, a mostra lo frau y dol, culpa negligentia gran que y ha hagut en dit tauler o cullidors, essent cert públich y notori que los marxants y botiguers de la present ciutat quiscun dia acudan en dita vila de Mataró a comprar robes y fer gran provisió d.ellas [...]». ACA. Generalitat. Visita del General, 56. Núm. 36. Año 1615.

${ }^{16}$ ACA. Generalitat. Visita del General, 77. Núm. 67.

17 «A notícia del procurador fiscal de la present visita és vingut que Joan Palau de Mataró [...] en diffarents ocasions ha venut $y$ ven vi als patrons o provehidors de las galeras y altres vexells strangers pera aportar-se'n y fer mercaderia sens fer-los pagar lo dret de General y Galeras per la exida de dit vi y en particular a las galeras de la senyoria de Gènova y a las galeras de Nàpols que [...] estiguesen en la plaja de Mataró y ara últimament se'n són anadas a las quals dit Palau vené molt gran quantitat de vi sens exigir dits drets de General y Galeras lo que fa per son proffit y utilitat pròpia per a poder ell sol vendrer dit vi al preu que vol de manera que los demés particulars de dita vila no poden vendrer a dits vexells llurs vins per lo que pagarian llurs drets, los quals no pagan comprant lo de dit Palau». ACA. Generalitat. Visita del General, 77. Núm. 67. 
sacerdote del templo parroquial y miembro de una de las familias que podían verse afectadas por las acaparadoras maniobras de Palau confirmaba las apreciaciones del procurador fiscal, citaba regalos y lisonjas del inculpado hacia los capitanes de las galeras para obtener el abastecimiento de sus naves, y cifraba el volumen de vino negociado en estas circunstancias en centenares de cargas $^{18}$. En el interrogatorio posterior, Palau reconoció haber abastecido las galeras «patrona real de la squadra de Spanya y Pimentela de la esquadra de Scicília» con 100 cargas de vino y otras 527 cargas destinadas a las galeras de Nápoles y también de Sicilia.

Retomando el curriculum de Jeroni Serra Arnau, hay que destacar que su polifacética personalidad no se debió manifestar únicamente en el mundo económico -en el que se movió con exquisita habilidad-, pues hay que hacer notar que, a pesar de las reiteradas visitas de que fue objeto y de los esfuerzos de diferentes procuradores fiscales, su actuación al servicio de los intereses de la Generalitat no dio lugar a ninguna condena que haya sido posible localizar.

La aproximación al curriculum de Jeroni Serra Arnau no estaría en modo alguno completa si se obviara su dimensión política y social en el seno de la comunidad en la que le tocó vivir.

Mataró experimentó durante la segunda mitad del siglo xvi y primeras décadas del siglo xvir un importante crecimiento demográfico y urbano que tuvo una de sus concreciones más significativas en el hecho que fuese amurallada ex novo durante este período, a instancias de la Corona por su importancia estratégica. Otro elemento significativo de su creciente importancia fue la concesión, otorgada por Felipe II, que le permitía tener representación en la Cort General de Cataluña. La primera convocatoria a la que la villa tuvo acceso fue la realizada en Monzón el año 1585. El representante de los mataroneses ante el máximo órgano deliberativo catalán fue Jeroni Serra Arnau. Sus habilidades políticas en la gran asamblea estamental son de destacar, y fue por su mediación que la villa consiguió incrementar el número de privilegios que constituían la carta magna del gobierno local ${ }^{19}$.

${ }^{18}$ El 27 de noviembre de 1623 Antoni Portell, presbítero, beneficiado de Santa Maria de Mataró, de 50 años declaraba «[...] he vist jo t. En ocasions que venien galeres en Barcelona $o$ en Palamós que dit Joan Palau en dita supplicatió nomenat feya molts grans diligenties $a b$ los patrons capitans de dites galeres per a vendrer vi festejant-los y regalant-los per a que li.n comprassen y de fet he vist jo t. En moltes ocasions que dit Palau ha venut molt vi que passava de centenars de càrregues a ditas galeras, que últimament hi són estades de Nàpols, viu jo, testimoni, los ne venien una bona partida que passava de cent càrregues y que si dit Palau pagava o dret de dit vi al General o no, que jo t. Me'n remet a la veritat que jo no y puch dir res». ACA. Generalitat. Visita del General, 77. Núm. 67.

${ }^{19}$ «Sia memòria a la Universitat y singulars de la vila de Mataró com los sinch privilegis que consecutivament se inserten apres del present full se obtingueren per lo honorable mossèn Hieronim Serra Arnau, mercader de dita vila de Mataró com a syndich de dita Universitat». Archivo Municipal de Mataró (AMM). Llibre segon de Privilegis. Fol. XXIX v. 
En el año 1589 conseguía nuevas gracias reales en las cuales, entre otras cosas, se concedía la celebración de dos ferias anuales en consideración a que «la dita vila de Mataró va cada dia augmentant y poblant se» ${ }^{20}$. Diez años más tarde, las diligentes gestiones políticas conseguían nuevos preceptos reales que reforzaban la autonomía y los derechos de la universidad de la villa, órgano de gobierno local. Dentro de esta copiosa lluvia de gracias reales -por paradójico que pueda parecer-, una no llegó a inscribirse en los libros de privilegios de la villa por la oposición que suscitó en el seno de la sociedad mataronesa: el privilegio rechazado contemplaba la posibilidad de crear una pequeña nobleza urbana que, inspirándose en la existente en Perpiñán, había de denominarse burgesos honrats, cuyos miembros podrían gozar de los privilegios propios del estamento militar. El privilegio tuvo una vida efímera ya que, una vez estudiado por la Universitat de la vila se consideró que era contrario y pernicioso para la comunidad y corrompía la gestión pública (regimen et administratio rei publicae dimimetur et corrumpetur $)^{21}$, ya que, si se llevaba a efecto esta prerrogativa, al cabo de pocos años una buena parte de los habitantes de la villa podrían alegar las exenciones de los militares, creando dificultades para una gestión ordenada de la sociedad.

¿Habría que dudar que Jeroni Serra Arnau fue una de las personas agraciadas con el flamante título de burgès honrat que mantuvo para sí y los suyos a pesar de la posición del gobierno local? La consecución de este título venía a coronar una intensa actividad en distintos órdenes de la población. No solamente ejerció la notaría, sino que se puede rastrear su trayectoria en todo el escalafón del sistema político, pasando por todas las magistraturas locales. Una personalidad de estas características tenía que despertar sentimientos contradictorios entre sus conciudadanos. Pierre Vilar se quejaba con cierta frecuencia de que el historiador no podía contar, entre sus fuentes, con los periódicos de la oposición política, debiéndose contentar en muchas ocasiones con las versiones oficiales de los hechos. En esta ocasión nos ha sido posible conocer el parecer de algunos ciudadanos sobre la gestión de Serra Arnau gracias a una lletra de desafiament que alguien pegó en lugar bien visible de la plaza pública cuando el ínclito protagonista de estas líneas ejercía las funciones de baile real de la villa²2. Sin poder

\footnotetext{
${ }^{20}$ Llibre segon de Privilegis. 31.VII.1589.

${ }^{21}$ ACA. Arx. Not. Mataró, 1026, 26.V.1600.

22 «Señors jurats de Mataró per molt honrats vos podeu tenir perquè teniu un tal balle, lo qual sap molt ben regir y havent-lo enviat a Monçó per síndich vostre lo qual ha tant per vosaltres alcansat com si fos un porch en lo stable, pus bé ha demanat lo bastó de Mataró per lo temps de la sua vida y lo rey, com a home molt discret, li ha dit que no lo y podia donar. Y també va demanar cadira per seure. Un els grandes de Castella digue-li que una banca se anàs a cercar. Lo que ell vos ha alcansat és que us ha despeses dos-centes lliures de axò ell ha ben trumfat per banquets y també bagasses molt prest ho hagués mercat y per axò és, conexent que ell té tot lo regiment en sa mà, perquè ell o té tot en sa mà y també a tots
} 
entrar a valorar las razones del anónimo autor del panfleto, es ya llegado el momento de argumentar la oportunidad de este dilatado excurso.

Uno de los más notables méritos de Miquel de Cervantes es el de haber ofrecido en su personaje central un retrato, sólo ligeramente distorsionado, de la realidad en que vivía la sociedad que vio alumbrar su obra. El mundo arcaizante, decadente, ridículo y ya periclitado que el Ingenioso Hidalgo representa provoca la hilaridad de muchos de los que le tratan, que -ingenuamente- no aciertan a ver en las alucinaciones del Quijote las contradicciones de su propio mundo. ¿Cómo no ver, por ejemplo, en la feroz lucha contra los molinos de viento transmutados en gigantes -de forma premonitoria- la impotencia de la Monarquía Hispánica para mantener su hegemonía de forma agónica? Y ¿cómo no contemplar el sarcasmo que envuelve al protagonista en la venta en la que se ha de armar caballero como una crítica feroz contra muchos de los rituales y convencionalismos en que se basaba la sociedad española a caballo de los siglos xVI y xvII?

La razón última de esta contraposición entre el mundo periclitado -que, metafóricamente, se vincula a las novelas de caballerías- y el mundo moderno, del que el Quijote es su primera manifestación novelada, radica en que el mundo que Cervantes dibuja con maestría, dentro de las ensoñaciones de la locura, se encontraba aún en la base de la cosmovisión de sus contemporáneos. El mérito de Cervantes fue presentar a sus conciudadanos una caricatura risible sin que la mayoría de ellos se apercibiera que era su propio retrato lo que tenían enfrente, sólo ligeramente desdibujado de la realidad por el manco genial, al igual que los espejos cóncavos o convexos acentúan o menguan las características de lo que reflejan. En este sentido, la realidad catalana que percibe Don Quijote es una realidad mediatizada por sus propias ensoñaciones: bandoleros, cabezas encantadas parlantes, galeras y corsarios, historias de amor como las que se dan entre la bella morisca y el caballero cristiano, etc. Un universo donde se dan la mano lo real y lo irreal, lo mágico y lo cotidiano, pues ¿no es ésa una de las características de esta obra cervantina?

Es posible hacer una interesante observación de estas dos visiones de la realidad que se dan en el Quijote analizando la descripción que Cervantes nos ofrece del hidalgo manchego: «lanza en astillero, adarga antigua, rocín flaco y galgo

vosaltres perquè sou bocamols y ell és tant superbo que ninguna cosa li podeu demanar. Per ço avisar-vos vull en balle que jo us faré posar lo peu pla perquè és tanta la vostra supèrbia que en lo món no té par y havent dit que és per del més ningú voler aver-les ab vós en poch perquè ho teniu tot dintre del puny y per ço jo vull veure a mi si.m podeu vènser vós en brivó y tota la vostra camarada los quals són tots com vós a hont primer és lo capità y l.altre és en Jofre y també Antoni Roig y un altre que.s diu Nicolau Pedró y en Dos Vall no ha de restar y molts altres los quals no.ls vull posar perquè veix no són tant mals ni assí tampoch no.m caben encara qui us fes assò és gran veritat. Vós en capità de infern e tots los assí posats y los altres innombrats los quals tots allí balaran per secula seculorum. Amen.» ACA. Arx. Not. Mataró, B-35, 21.II.1586. 
corredor. Una olla de algo más vaca que carnero [...] lentejas los viernes, algún palomino los domingos consumían las tres partes de su hacienda [...] gran madrugador y amigo de la caza [...] los ratos que estaba ocioso, que eran los más del año $[\ldots]^{23}$. Si se compara esta descripción del héroe cervantino con la realidad de Jeroni Serra Arnau, que coronó su dilatada vida pública con un título nobiliario que, salvando todas las distancias, podría corresponderse con la hidalguía del manchego, puede otra vez divisarse, no sólo una diferente situación económica, sino que se perciben perfectamente estas dos categorías que -de forma muy elemental- cabría calificar como prototipo de antiguo y de moderno.

Así, el inventario de los bienes de Jeroni Serra Arnau nos ofrece una rica descripción del ambiente que le rodeaba en una mansión que, aún hoy, es uno de los edificios más nobles de Mataró. El ambiente que presenta el notario en su meticuloso relato está definido por un extenso mobiliario y un rico ajuar en el que no faltan elementos suntuarios: «un parament per tota la dita cambra de guadamacils pintats de or y altres colors», la seda en cortinas y cobertores; la plata como elemento de exhibicionismo social en forma de jarras, cubiertos, saleros, candeleros, tazones. Pero, además, otro elemento dotado de un gran valor simbólico: una pintura al óleo representando al protagonista de estas líneas junto con su familia. Junto con estas presencias también hay ausencias relevantes y clamorosas: los únicos libros individualizados en el inventario son los propios del negocio.

$\mathrm{Y}$ es que la distancia entre ambos personajes es de proporciones astronómicas, así en lo material como en lo ideológico. Así, se cita una frase en El Quijote, parafraseando a Bernard Duguesclin en el suceso de Montiel, que, sin lugar a dudas, Jeroni Serra Arnau podría haber considerado para su flamante escudo de armas: «ni quito rey ni pongo rey, [...] sino ayúdome a mí que soy mi señor» ${ }^{24}$. Pero esta cita, como es obvio, no pertenece al universo mental de Don Quijote, sino al de Sancho, por el que muchas veces habla el más común de los sentidos, aunque sea el menos elevado.

A pesar de todo lo dicho, hay, quizás, un punto de acercamiento -más que en común- entre la historia de Don Quijote en Barcelona y la trayectoria de Serra Arnau. Después que las galeras en las que se encontraban Don Quijote y Sancho detuvieran la nave corsaria argelina e interrogaran al arráez, éste, descubierta su condición femenina, confesó ser «de aquella nación más desdichada que prudente, sobre quien ha llovido estos días un mar de desgracias, nací yo, de moriscos padres engendrada [...] sin que me aprovechase decir que era cristiana [...] tuve una madre cristiana y un padre discreto y cristiano, ni más ni menos; mamé la fe católica en la leche» ${ }^{25}$. Como es sabido, estas declaraciones movieron el ánimo de

\footnotetext{
${ }^{23}$ ACA. Arx. Not. Mataró, 1026, 26.V.1600.

${ }^{24}$ ACA. Cancelleria, Registre 4876, Fol. 244v y ss.

${ }^{25}$ El Quijote, I-I.
} 
Don Quijote para planear un atrevido rescate del amante de la morisca en Argel. Pues bien, el frío lenguaje del notario nos hace conocer que Jeroni Serra Arnau era propietario de una esclava llamada Ángela, blanca, cristiana, nacida en Granada -¿̇morisca vinculada a la revuelta de las Alpujarras?-, que vendió al caballero Bartolomé de Palma. Esta operación pudo haber tenido, también, su componente romántico-caballeresco, pues el comprador había sido propietario del esposo de la cautiva. La actitud de Serra Arnau dista de la predisposición altruista de Don Quijote. Se limitó, sencillamente, a embolsar 50 libras por la compra-venta ${ }^{26}$.

Sin poner ninguna objeción a que las dos realidades representadas por Don Quijote y Jeroni Serra pudieran darse en un mismo plano temporal y espacial, considero que la realidad que refleja el segundo, su mentalidad y actitudes se pueden documentar en numerosos ámbitos catalanes de esta época. Quizás el elemento más novedoso consista en poder afirmar que, en el caso catalán, se dan, en un mismo momento, personajes como Serra y también individuos que viven un mundo similar al del Hidalgo Ingenioso; por ejemplo, formando parte de las parcialidades de nyerros y cadells. Lo significativo no es esta dualidad, sino el que la primera opción, la que hemos dado en llamar moderna, se generalizase y desplazase a la segunda, marcando así un camino propio de evolución para la sociedad catalana.

$\mathrm{Si}$, en lugar de ser Don Quijote quien pisara la calles de Barcelona, hubiese sido Don Alonso Quijano el que transitara por las tierras de Cataluña, con «juicio ya, libre y claro, sin las sombras caliginosas de la ignorancia» ${ }^{27}$, su percepción de la realidad hubiera sido muy aproximada a la reflejada en la sucinta biografía del burgués honrado de nuevo cuño: una sociedad tremendamente activa. Con una realidad emergente de mercaderes y negociantes afincados en los fraudes y las ocultaciones fiscales, exportando productos de origen agrario, pesca salada pero, también, manufacturados como el vidrio, la cuchillería, la clavazón, cueros, e introduciendo en Cataluña tejidos de diversas procedencias que, posteriormente, se distribuirían por el mercado peninsular. Esta realidad era, sin duda, muy distinta a la esplendorosa Edad Media catalana. Los jinetes apocalípticos se autoconvocaron en los condados catalanes en la baja Edad Media. Crisis sociales, políticas, económicas y demográficas apearon a Cataluña del lugar preeminente que había ocupado en el Mediterráneo y en el contexto peninsular. A finales del siglo Xv se dan la cifras más bajas de actividad económica en el Principado.

Tradicionalmente, la historiografía, desde la etapa romántica hasta fechas relativamente recientes, se ha venido refiriendo a los siglos XVI y XVII como siglos de decadencia económica y cultural. Siglos de oscuridad se les llamaba por los que se encontraban deslumbrados por los logros medievales o por el brillante despegue

\footnotetext{
${ }^{26}$ El Quijote, II-LX

${ }^{27}$ El Quijote, II-LXIII
} 
del siglo XVIII. El maestro Pierre Vilar fue uno de los primeros en percatarse de que, en el último tercio del siglo xviI, se estaban poniendo las bases del redreçament catalán del siglo siguiente, pero que, con anterioridad a este período, entre 1598 y 1640 se dio una importante crisis industrial seguida, no obstante, de una muy importante revitalización de las zonas situadas más allá del estricto marco barcelonés ${ }^{28}$.

La importancia de este desarrollo del marco rural ha sido recientemente puesto de relieve en dos obras que focalizan el estudio de la actividad económica catalana en este período ${ }^{29}$. A la vista de estos y otros trabajos puede hoy afirmarse que la crisis demográfica -consecuencia de los estragos con que se cerró la Edad Media- empezó a cerrarse con la llegada de inmigración francesa, que ocupó tierras que habían quedado sin cultivar y constituyó mano de obra barata para todas las actividades que la requerían ${ }^{30}$.

Con esta base, en algunas zonas de litoral catalán empezaron a producirse cambios muy significativos. La antigua payesía de mas empezó a vislumbrar nuevas forma de incrementar la productividad de sus predios. Se dieron al mismo tiempo, y según las características de la zona, tres posibilidades de modificar la explotación de la tierra. Una primera opción fue orientar la clásica trilogía mediterránea hacia aquellos cultivos que tuvieran mayores posibilidades de comercialización en los nuevos circuitos que el descubrimiento del Nuevo Mundo trazó. En el caso catalán, ejemplarizado en las zonas del Maresme primero y, posteriormente, del Penedès, se produjo una tendencia creciente hacia el monocultivo vitícola, cuyos frutos, primero vinificados y posteriormente destilados, alcanzarían Lisboa y el Mar del Norte antes del fin del siglo Xvir ${ }^{31}$. Otra opción de los titulares de tierras era la de ceder parcelas en contrato enfitéutico, opción que permitía a labradores sin tierras, jornaleros o artesanos acceder a la producción directa de productos agrarios. La tercera opción, también muy interesante desde el punto de vista económico, era la de convertir las rentas agrarias en rentas urbanas, adaptando las tierras a las necesidades de parcelación de los núcleos urbanos en crecimiento $^{32}$.

Esta nueva dinámica productiva actuó como motor económico y social en los ámbitos en que se dio, generando nuevos grupos sociales y profesionales que se

\footnotetext{
${ }^{28}$ Jeroni Serra Arnau vendió a Bartolomé de Palma «milite stipendiario sive entretingut per sua regiam magestatem oriundus civitate Oran, terrea Africae [...] quondam servam meam albam chirstianam nomine Angelam nationis Regni Granattae in Hispania filiam legittimam et naturales Didaci de Crece civitatis Granate et Hieronima de Vallasco illius uxoris aetatis viginnti quatuor annorum parum plus vel minus uxorum Francisci Santiago servi qui fuit vestre dicti emptoris las senyas que tiene son blanca con una senyal de lunar debaxo de la naris drexa [...] Pretium vero predictorum quae vobis vendo est quinquaginta librarum barcinane». ACA. Arx. Not. Mataró, 229, 8.VIII.1620.

${ }^{29}$ El Quijote, II-LXXIV

${ }^{30}$ Vilar (1964), Vol. II, pp. 373 y ss.

${ }^{31}$ García Espuche (1998); Giménez Blasco (2001).

${ }^{32}$ Nadal y Giralt (1960).
} 
incardinaron en el tejido productivo, produciendo un modelo nuevo, capaz de acumular riqueza con mucha más facilidad que el vigente con anterioridad, por lo cual su éxito se extendió a todas las zonas donde era practicable. La trayectoria económica de Jeroni Serra Arnau fue uno de los más claros exponentes de este modelo.

Por su parte, Alberto García Espuche ha hecho hincapié en dos fenómenos muy importantes para este período: la descentralización y la especialización del territorio. La capital del Principado, que se había venido tomando como pulsómetro único de la realidad de todo el territorio catalán, se ha revelado ineficaz para identificar una descentralización y especialización de las actividades económicas a lo largo y ancho de todo el territorio. Las dificultades de los textiles catalanes, demasiado anclados aún en el pasado, no podían competir con las producciones extranjeras que penetraban por el litoral. Pero, aún así, las zonas del interior Sabadell, Terrassa, Vic, Torelló, Igualada fueron centros productivos importantes para abastecer el mercado local. El cuero, ya en estas fechas procedente de América, formaba un renglón singular de la economía de la época, al ser un producto de uso mucho más generalizado que en la actualidad. Son numerosos los tratantes que compran el cuero en Sevilla y lo distribuyen en Cataluña ${ }^{33}$. Olot fue el centro que experimentó un crecimiento espectacular en este sentido ${ }^{34}$.

El vidrio tuvo en la Cataluña de esta época uno de sus momentos más gloriosos, siendo Mataró el primer centro indiscutible de esta actividad en los siglos XVI-XVII. Citar la presencia de hornos de esta industria de época romana es sólo una forma de explicar el arraigo de esta actividad en la capital del Maresme: en el año 1503, Felipe el Hermoso se desplazó desde Barcelona a esta población para contemplar el trabajo de los vidrieros al que el cronista del viaje no regateó elogios $^{35}$, y en el año 1592 se firmaba la constitución de una compañía entre el mercader, avecindado en Madrid, Pedro de Limia y el vidriero mataronés Genís Tremolet $^{36}$.

Justina Rodríguez ha interpretado que uno de los motivos que originó el éxito de la vidriería mataronesa fue su éxito en imitar la producción veneciana del vetro cristallino $^{37}$. Sea por esta u otras causas, lo cierto es que los vidrios de Mataró se extendieron por vía marítima a distintos puntos del litoral hispánico y también norteafricano y, a lomos de mulas, se desplazaron por Aragón, Navarra, Castilla y

\footnotetext{
33 Torras Elías (1998).

${ }^{34}$ García y Guàrdia (1989).

35 Torras Ribé (1991).

${ }^{36}$ García Espuche (1998), p. 200.

37 «Et son là faiets les plus ouvrages de voires (verres) et de cire qui soient au monde. Le jordi (19 janvier,1503) Monseigneur alla au dehors de la ville vioir ung jour oú on faiet voires (verres) de cristallin très beaus ». Gachard (1876). Vol. I, p. 257. Cfr. Rodríguez (1986), p. 1016.
} 
Andalucía. Existe una dinastía de vidrieros, los Roig -conocidos en Castilla como Roche- que, a través de diferentes arrieros, desplegaron una intensa actividad en el centro peninsular, teniendo bien presente como mercadería de retorno la lana segoviana, muy valorada por los mercaderes genoveses. Gracias a una de estas operaciones, los Roig satisficieron el encargo que de vidrios finos les había hecho Alonso González Muñiz, «vidriero de su majestad» ${ }^{38}$.

Estos últimos datos nos permiten entrar a valorar otro elemento interesante de la economía catalana de la época: la existencia de una notable diáspora de sus naturales por diversos territorios hispánicos. Martínez Shaw señaló en su momento la pronta implicación catalana en la carrera de Indias ${ }^{39}$. Eloy Martín Corrales hizo lo propio al analizar el comercio catalán con el norte de África y con la Andalucía Oriental $^{40}$, y, por su parte, García Espuche ha estudiado las colonias catalanas en Madrid, Medina del Campo y en la que él mismo llama la escala zaragozana ${ }^{41}$.

En contraste con estas luces, existían en el panorama catalán zonas oscuras, en las cuales las dificultades de adaptación a las nuevas necesidades y requerimientos de la sociedad eran mucho mayores. Las dificultades eran evidentes en Barcelona, en parte víctima de su propio esplendor capitalino. Si los mercaderes buscaban otros puertos donde descargar sus mercaderías era también, en parte, debido a la fiscalidad de la ciudad condal, que contrastaba con la de otros núcleos urbanos mucho menos exigentes, y también menos presionados por las autoridades centrales de la monarquía en sus demandas económicas. Asimismo, los núcleos urbanos que habían destacado durante la etapa medieval en la actividad manufacturera -Barcelona, Girona, Tortosa, etc.- habían desarrollado un rígido sistema gremial que había llegado a esclerotizar buena parte de la actividad económica que estaba bajo su control, que no era poca. Así se explica que las industrias que se desarrollaron en el siglo xvı lo hicieran en esos núcleos urbanos periféricos al centro político catalán, debido a una fiscalidad más baja, a la inexistencia de regulaciones gremiales restrictivas y a la existencia de una mano de obra campesina que podía emplearse en amplios períodos improductivos en el trabajo agrícola, realizando labores de tipo manufacturero bajo el control de los mercaderes urbanos.

Es en este marco en el que desarrollaron su actividad personajes tales como Jeroni Serra Arnau. Sin ninguna relación con las viejas dinastías de mercaderes

\footnotetext{
${ }^{38} \mathrm{El}$ objeto de la compañía era fabricar «en el horno de vidrio que tiene (Genís Tremolet) en la dicha villa de Matarón los quales vidrios se han de lebar y traer en los reynos de Castilla y de Aragón y en otras partes que fueran bien vistas a las dichas partes para que allí se puedan vender con más beneficio de la dicha compañía». Archivo Histórico Municipal de Barcelona, Notariales IX, 6.

${ }^{39}$ Rodríguez (1986)

${ }^{40}$ Giménez Blasco (2001).

${ }^{41}$ Martínez Shaw (1995).
} 
barceloneses, que en estos momentos dormitaban bajo los laureles de sus títulos de ciutadans honrats, dedicados a actividades rentistas. Esta burguesía de nuevo cuño emergió en las poblaciones de segundo orden, y tanteó todos los ámbitos susceptibles de generar beneficios económicos, estimulando toda la economía de la época. Se convirtieron en el capital humano imprescindible en cualquier proceso de desarrollo. Llegado el momento, no dudaron en acceder a los niveles sociales superiores por la vía del ennoblecimiento. Éste, además del prestigio evidente que conllevaba, tenía implicaciones mucho más pragmáticas, como, por ejemplo, liberarse de los molestos alojamientos militares que recaían con la pesadez de una maldición bíblica sobre el común de la población.

Las crisis centrales del Xviı ralentizaron, y en algún momento paralizaron, todo el movimiento económico que se había desarrollado en el microcosmos catalán durante el siglo. Pero no consiguieron abortarlo, y surgiría con fuerza en el último cuarto para dar a luz la espectacular realidad del siglo XvIII catalán que los contemporáneos no dudaron en calificar como un nuevo vuelo del ave Fénix.

Para bien o para mal, el espíritu de Alonso Quijano se había impuesto al de Don Quijote.

\section{FUENTES:}

Archivo de la Corona de Aragón (Barcelona)

\section{BIBLIOGRAFIA}

ELLiotT, J. H. (1977): La rebelión de los catalanes 1598-1640. Madrid.

Ferro, V. (1999): El Dret Públic Català. Les institucions a Catalunya fins al Decret de Nova Planta. Vic.

Gachard, M. (1876): Collection des voyages des souverains des Pays-Bas. «Voyage de Philippe le Beau en Espagne, en 1501». Bruselas.

García Espuche, A. (1998): Un siglo decisivo. Barcelona y Cataluña 1550-1640. Barcelona.

Garcia, A. y GuÀrdiA, M. (1989): La construcció d'una ciutat: Mataró, 1500-1900. Barcelona.

Giménez Blasco, J. (2001): Mataró en la Catalunya del segle xVII. Un microcosmos en moviment. Mataró.

Llovet, J. (2000): Mataró dels orígens de la vila a la ciutat contemporània. Mataró.

MARTí, A. (1996): Visió de Mataró a través de plets i discòrdies (segles XVII i XVIII). Mataró.

Martín CoRrales, E. (1995): «El comercio de Cataluña con Andalucía Oriental (1487-1659)». Primer Congreso de Historia Catalana-Andaluza. L'Hospitalet de Llobregat: Fundació Gresol y Ayuntamiento de l'Hospitalet. 
- (2000): Comercio de Cataluña con el Mediterráneo musulmán (siglos XVI-XVIII). El comercio con los «enemigos de la fe». Barcelona.

Martínez SHAw, C. (1995): «Las relaciones comerciales entre Cataluña y la Baja Andalucía en los siglos XVI y xvII: una recapitulación y una reflexión». Primer Congreso de Historia Catalana-Andaluza. L’Hospitalet de Llobregat: Fundació Gresol y Ayuntamiento de l'Hospitalet.

Nadal, J. y Giralt, E. (1960): La population catalane de 1553 à 1717. L'immigration française et les autres facteurs de son développement. París.

Recopilació de diferents vots, y altres documents en justificacio dels drets de la Generalitat de Cahalunya. (1969): Barcelona: Impresa por Rafael Figuerò.

Rodríguez, J. (1986): «El vidrio veneciano de los siglos XV al XVII y su influencia en Cataluña». Madrid: Universidad Nacional de Educación a Distancia. Tesis Doctoral..

Torras Elias, J. (1998): Productes vitícoles i integració mercantil a Europa, ss. XVI-XVII. Barcelona.

Torras Ribé, J. (1991): Curtidores y tenerías en Cataluña: organización de un oficio preindustrial (siglos XIV-XIX). Igualada.

VILAR, P. (1964): Catalunya dins l'Espanya Contemporània. Barcelona. 


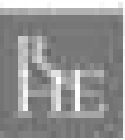

\section{Recrivts}

in Historia

Economica jermul of

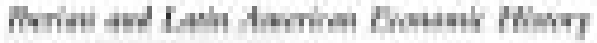

\section{Nuevas ideas Nuevos horizontes}

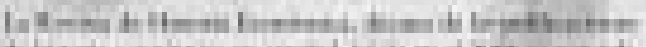

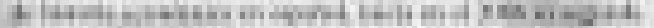

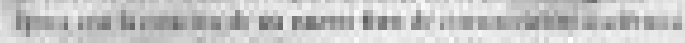

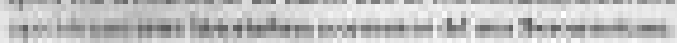

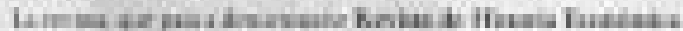

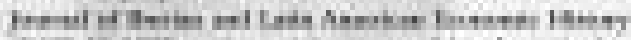

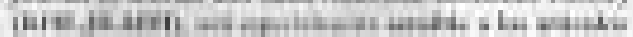

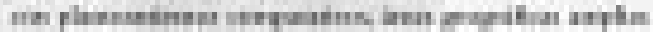

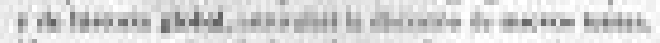

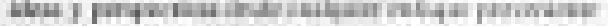

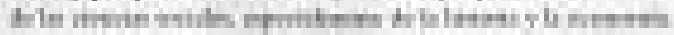

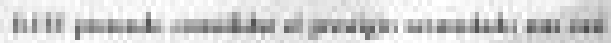

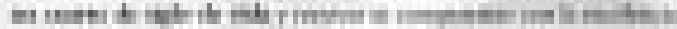

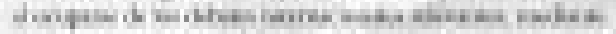

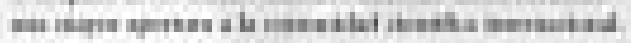
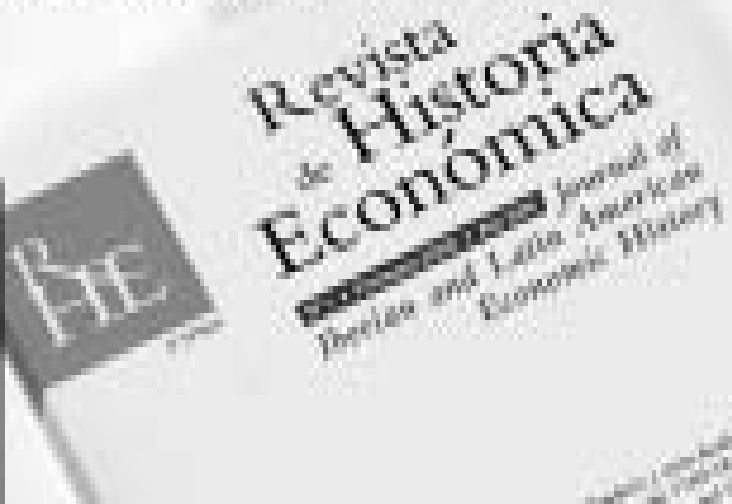

Hith

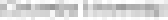

Intratint

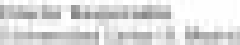

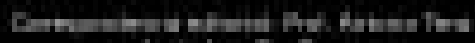

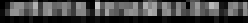

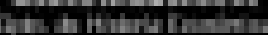

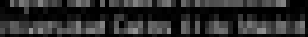

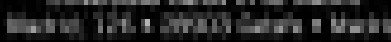

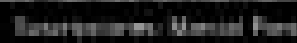

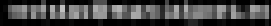

Hin why

in tran in the thit 
